\title{
EFEKTIVITAS MEDIA AUDIO PEMBELAJARAN BAHASA INGGRIS BERBASIS LAGU KREASI DI KELAS LIMA SEKOLAH DASAR
}

\author{
Ratminingsih, N. M. \\ Jurusan Pendidikan Bahasa Inggris, \\ Universitas Pendidikan Ganesha, Indonesia \\ e-mail: made_ratminingsih@yahoo.com.au
}

\begin{abstract}
Abstrak
Tujuan penelitian ini adalah untuk melaporkan efektivitas media audio berbasis lagu kreasi yang dikembangkan berdasarkan tema untuk siswa kelas lima sekolah dasar. Setelah divalidasi oleh dua orang ahli dalam hal isi dan kualitas, media yang dikembangkan diimplementasikan di SDN 1 Sukasada yang melibatkan 16 orang siswa. Desain penelitian menggunakan desain before and after treatment. Hasil penelitian membuktikkan bahwa media audio efektif meningkatkan kompetensi Bahasa Inggris siswa kelas lima yang ditunjukkan dari perolehan rerata hasil belajar dari 6,69 yang terkategori cukup sebelum tindakan menjadi 8,31 yang terkategori baik setelah tindakan. Di samping itu, hasil kuesioner membuktikan bahwa semua siswa $(100 \%)$ menunjukkan persepsi positif terhadap pemanfaatan media audio berbasis lagu. Mereka menjadi lebih termotivasi untuk belajar karena melalui lagu pembelajaran menjadi menyenangkan, menarik, dan materi lebih mudah dipahami.
\end{abstract}

Kata kunci: media audio, lagu kreasi

\begin{abstract}
This article aims at reporting the effectivenes of a scripted song-based audio media developed centered upon themes for fifth graders of elementary schools. After being validated by two experts to determine the content validity and the quality, the media was implemented in SDN 1 Sukasada involving 16 students. The design of research utilized before and after treatment. The result proved that the audio media was effective to improve the fifth grade students' English competence shown from the attainment of mean score of learning achievement, from 6.69 categorized as moderate before tratment to become 8.31 classified as good after treatment. Moreover, the result of questionnaire shows that all students $(100 \%)$ had a positive perception towards the use of a scripted-song based audio media, in which they were more motivated to learn because through the songs, the learning process became fun, interesting and thus the material was easier to understand.
\end{abstract}

Keywords: audio media, scripted songs 


\section{PENDAHULUAN}

Bahasa Inggris menjadi mata pelajaran muatan lokal di sekolah dasar yang diperkenalkan dari kelas empat sampai dengan kelas enam sejak tahun 1994. Menurut Harmer (1983), pengenalan bahasa Inggris sejak awal didasari oleh suatu konsep pedagogis bahwa semakin dini usia seseorang diperkenalkan dengan bahasa target, semakin cepat dan semakin bagus penguasaan dan pemerolehan anak terhadap bahasa yang dipelajari.

Secara yuridis, Permen No 22 tahun 2006 tentang standar isi menegaskan bahwa pembelajaran bahasa Inggris di sekolah dasar bertujuan agar peserta didik memiliki kemampuan: (1) Mengembangkan kompetensi berkomunikasi dalam bentuk lisan secara terbatas untuk mengiringi tindakan (language accompanying action) dalam konteks sekolah, dan (2) Memiliki kesadaran tentang hakikat dan pentingnya bahasa Inggris untuk meningkatkan daya saing bangsa dalam masyarakat global." Berdasarkan tujuan tersebut, maka aspek mendengarkan (listening) dan berbicara (speaking) harus ditekankan tanpa mengesampingkan aspek kosakata, gramatika, pelafalan, dan aspek menulis (writing) dan membaca (reading).

Dalam kurikulum 2013, pembelajaran bahasa Inggris tidak diberikan secara eksplisit dalam struktur kurikulum, namun mata pelajaran bahasa Inggris dapat diberikan sebagai mata pelajaran muatan lokal, dan sampai saat ini banyak sekolah masih berkiblat dengan KTSP dalam hal pemberian pelajaran bahasa Inggris sebanyak 2 jam pelajaran dalam 1 minggu. Dapat dikatakan bahwa tujuan pembelajaran bahasa Inggris di sekolah dasar adalah untuk mencapai kompetensi berkomunikasi oral yang mengintegrasikan semua komponen bahasa yaitu kosakata, gramatika, dan pelafalan. Kompetensi bahasa Inggris siswa diukur melalui capaian hasil belajar. Hasil belajar adalah perubahan tingkah laku sebagai hasil belajar yang mencakup aspek kognitif, psikomotor dan afektif. Sementara itu, Dimyati (2006) mendefinisikan hasil belajar sebagai hasil dari suatu interaksi tindak belajar dan tindak mengajar. Dengan demikian, yang dimaksudkan dengan hasil belajar dalam artikel ini adalah hasil belajar bahasa Inggris siswa kelas lima SD selama 2 sesi pembelajaran dengan topik Sports yang ditunjukkan dari kemampuan mereka menjawab pertanyaan-pertanyaan terkait dengan materi yang diajarkan sebagai tindak mengajar oleh guru dan tindak belajar oleh siswa.

Brown (1994) menyatakan bahwa terdapat lima kategori yang harus diperhatikan guru dalam merancang pembelajaran bahasa Inggris yang sukses bagi anak-anak, yaitu (1) Intellectual Development, (2) Attention Span, (3) Sensory Input, (4) Affective Factors, dan (5) Authentic, Meaningful Language.Intellectual development dimaksudkan bahwa anak-anak sampai pada usia 11 tahun masih dalam fase pertumbuhan intelektual yang dinamakan oleh Piaget "concrete operation". Jadi, semua materi pembelajaran hendaknya dikemas secara konkret, dan menghindari konsep abstrak. Dengan keterbatasan ini, segala bentuk pembelajaran berupa aturanaturan, penjelasan-penjelasan, dan pembahasan kebahasaan yang bersifat 
abstrak hendaknya dilaksanakan dengan sangat hati-hati, dan diusahakan untuk dipresentasikan secara konkret. Dari dimensi attention span, konsentrasi anak bergantung pada pengemasan pembelajaran oleh guru. Mereka tidak akan memperhatikan pelajaran jika materi yang diajarkan membosankan, tidak bermakna, dan terlalu sulit. Sensory input menyangkut pembelajaran hendaknya melibatkan semua indra anak-anak, baik itu penglihatan, pendengaran, rasa, penciuman, dan sentuhan. Affective factors dimaksudkan agar pembelajaran dapat membuat anak-anak memiliki sikap senang dan nyaman dalam belajar, dan authentic meaningful language dimaksudkan agar bahasa yang diajarkan bersifat autentik dan bermanfaat dalam kehidupan. Willing (dalam Chitravelu, Sithamparam, \& Teh, 2005) menegaskan bahwa anakanak yang bertipe kongkret (concrete learner) akan menyenangi strategi pembelajaran yang memanfaatkan games, pictures, films, cassettes, videos, dan lain-lain.

Namun demikian, berbagai fakta mengindikasikan bahwa masih terdapat berbagai kendala di lapangan dalam pelaksanaan pembelajaran yang memadai. Hasil survei Ratminingsih (2010) kepada guru-guru bahasa Inggris di SD di Kecamatan Buleleng dan Sukasada membuktikan bahwa guru pengajar bahasa Inggris belum memiliki latar belakang pendidikan yang memadai. Guru cenderung mengimplementasikan pembelajaran dengan melafalkan kosakata melalui drills dan menjelaskan kosakata bahasa Inggris melalui terjemahan ke dalam bahasa pertama (dalam Ratminingsih, 2010). Selanjutnya, hasil wawancara dalam kegiatan P2M di Kecamatan Sukasada yang diikuti oleh 25 orang guru bahasa Inggris (Ratminingsih \& Budasi, 2012), menunjukkan bahwa mereka tidak pernah menggunakan media pembelajaran inovatif audio (lagu-lagu kreasi khusus) dan hanya berpedoman pada buku.

Permasalahan di atas, khususnya pada permasalahan media dapat diselesaikan dengan pengembangan media pembelajaran yang lebih inovatif, agar guru dapat memvariasikan pembelajaran yang dapat menghadirkan kesenangan dalam proses pembelajaran kepada siswa. Gagne \& Briggs (1974) memaparkan bahwa media pembelajaran merupakan alat yang secara fisik digunakan untuk menyampaikan isi materi pelajaran, yang terdiri dari buku, modul, teks terprogram, tape recorder, kaset, video camera, video recorder, film, slide, foto, gambar, grafik, televisi, komputer, dan sebagainya. Lebih jauh Arsyad (2011) menjelaskan bahwa apabila media itu membawa pesan-pesan atau informasi yang bertujuan instruksional atau mengandung maksud-maksud pengajaran, maka media itu disebut media pembelajaran. Maka, dapat disimpulkan bahwa media pembelajaran adalah alat-alat fisik yang digunakan dalam menyampaikan informasi, yaitu berupa materi pembelajaran kepada peserta didik.

Kemp (dalam (Ramendra \& Ratminingsih, 2006, 2007) mengelompokkan alat bantu pembelajaran ke dalam tiga kelompok, yaitu (1) alat bantu dengar (audio aids), antara lain radio dan tape recording, (2) alat bantu pandang (visual aids), antara lain papan tulis, benda-benda nyata 
(realia), gambar, flash cards, chart, slide, dan (3) alat bantu pandang dan dengar (audio-visual aids), yaitu video dan film. Selanjutnya, berdasarkan perkembangan teknologi, media pembelajaran dikelompokkan menjadi empat kelompok, yaitu (1) media hasil teknologi cetak, (2) media hasil teknologi audio-visual, (3) media hasil teknologi komputer, dan (4) media hasil gabungan teknologi cetak dan komputer (Arsyad, 2011).

Berdasarkan paparan di atas, maka lagu-lagu kreasi khusus yang direkam pada kaset atau CD yang dikembangkan dalam penelitian ini dapat dikelompokkan ke dalam media pembelajaran audio, yaitu alat bantu pembelajaran yang didengar oleh peserta didik untuk mendapatkan informasi berupa materi-materi pelajaran bahasa Inggris sesuai dengan tema yang diajarkan. Dalam proses pembelajaran, guru menggunakan mesin berupa $C D$ player atau komputer untuk mempresentasikan materi.

Media pembelajaran yang baik adalah media yang dapat membantu proses transfer materi pelajaran dengan baik, menarik perhatian peserta didik, menciptakan suasana belajar yang menyenangkan, dan dapat memotivasi mereka. Arsyad (2011) menegaskan bahwa proses pembelajaran dapat menjadi lebih dinamis dan akan mencapai sasaran yang diinginkan jika ditambahkan alat bantu atau media, seperti media audio-visual, cetak, proyektor, film, permainan, dan sebagainya. Yassaei (2012) menambahkan bahwa salah satu cara yang paling terkenal untuk menciptakan konteks bermakna untuk pembelajaran bahasa Inggris adalah melalui penggunaan media, yang dapat ditampilkan melalui berbagai format, seperti cetak, audio, dan visual. Sementara Hamalik (dalam Arsyad, 2011), mengemukakan bahwa pemakaian media pembelajaran dalam proses belajar mengajar dapat membangkitkan keinginan dan minat yang baru, membangkitkan motivasi dan rangsangan kegiatan belajar, dan bahkan membawa pengaruh psikologis terhadap siswa. Sejalan dengan pendapat Hamalik, Shin (2006) juga mengungkapkan bahwa salah satu cara untuk meningkatkan perhatian dan keterlibatan siswa dalam aktivitas belajar diperlukan adanya alat pendukung berupa alat-alat bantu visual, mainan, boneka atau objek-objek lain yang berwarna-warni, yang sesuai dengan cerita atau lagu yang digunakan dalam pembelajaran, sehingga pembelajaran bahasa menjadi lebih mudah dipahami.

Dari semua pendapat di atas, dapat disimpulkan bahwa media pembelajaran merupakan salah satu faktor penting yang dapat membuat proses pembelajaran berhasil. Media yang dikemas dengan menarik dapat memotivasi siswa agar mau dan mempertahankan belajarnya, mempermudah proses belajar, membuat pembelajaran efektif dan efisien, dan kemudian meningkatkan hasil belajar.

Dengan demikian, tugas guru adalah untuk membuat pembelajaran lebih menarik, hidup dan menyenangkan. Salah satunya adalah melalui pemanfaatan media pembelajaran audio (kaset atau CD). Media audio selain dapat menghadirkan kesenangan, suasana rileks, yang terpenting adalah dapat memberikan contoh pajanan bahasa yang kaya dengan aspek 
kebahasaan, seperti kosakata, gramatika, lafal, tetapi juga keterampilan berbahasa (mendengarkan, berbicara, membaca, dan menulis). Terlebih lagi, bagi para guru yang berlatar belakang non kependidikan bahasa Inggris, mereka dapat dibantu diberikan model bahasa yang akurat dari segi lafal dan intonasi dengan mengulang-ulang media audio yang tersedia. Oleh karena itu, dalam penelitian (Ratminingsih \& Budasi, 2014) dikembangkan media pembelajaran audio, yaitu CD pembelajaran berbasis lagu-lagu kreasi berdasarkan tema pada kelas lima sekolah dasar.

Menurut Schoepp (2001), lagu menjadi bagian yang integral dari pengalaman berbahasa manusia. Flattum (2008) menambahkan bahwalagu merupakan kombinasi melodi dan lirik dengan harmoni, irama atau bit. Lagu biasanya memiliki struktur berupa pengulangan-pengulangan syair dan korus. Lagu kreasi yang dimaksudkan dalam penelitian ini adalah lagu-lagu yang liriknya diciptakan oleh peneliti berdasarkan tema, sementara melodinya diambil dari irama musik dari lagu anakanak Indonesia atau asing yang sudah dikenal. Lebih lanjut, Shtakser (2012) menjelaskan bahwa musik dan lagu dapat menciptakan atmosfer belajar yang baik dalam kelas. Brewster, Ellis, \& Girard (1992) juga menambahkan bahwa lagu merupakan strategi yang ideal untuk belajar bahasa karena di dalam lagu terdapat pengulangan-pengulangan kosakata dan struktur bahasa serta irama yang dapat meningkatkan ketertarikan siswa dalam belajar. Selain itu, Malley mengemukakan dua manfaat utama penggunaan musik dan lagu dalam pembelajaran bahasa, yakni lagu mudah dihafalkan dan sangat memotivasi pebelajar (dalam Murphey, 1992). Murphey menambahkan bahwa musik dan lagu lama disimpan dalam ingatan, dan dapat menjadi bagian dari diri kita serta mudah dimanfaatkan di dalam kelas.

Griffee (1992) lebih lanjut mengemukakan 6 keuntungan penggunaan lagu dan musik dalam kelas bahasa, yaitu (1) Classroom atmosphere: lagu dan musik digunakan untuk memberikan suasana kelas yang menyenangkan, (2) Language input: lagu dan musik digunakan untuk memberikan pajanan irama bahasa, (3) Cultural input: lagu dan musik (khususnya musik pop) memberikan pengenalan budaya, (4) Text: lagu digunakan sebagai teks pembelajaran, seperti halnya puisi, cerita pendek, dan novel, (5) Supplement: lagu digunakan sebagai pelengkap dari buku teks, dan (6) Teaching and Student interest: lagu dapat digunakan untuk mengajarkan percakapan, kosakata, struktur gramatika, lafal, latihan pola, dan pemantapan ingatan. Paul \& Chan (2010) menambahkan lagu membuat anak-anak lebih mudah mengingat katakata dan pola-pola serta potonganpotongan natural dari bahasa (chunks of language).

Dari semua pendapat di atas, dapat disimpulkan bahwa lagu memiliki berbagai manfaat untuk mengajarkan bahasa secara lebih menyenangkan yang dapat mempermudah siswa mengingat kata, pola bahasa, dan potongan-potongan natural dari bahasa, serta dapat melibatkan perasaan mereka secara lebih mendalam pada pembelajaran.

Ada beberapa jenis lagu yang dapat digunakan untuk tujuan mengajar 
yang berbeda, yaitu lagu, syair, dan syair yang dilagukan pendek-pendek (Brewster et al., 1992). Mol (2012) mengemukan beberapa jenis lagu, seperti syair anak-anak, musik pop kontemporer, dan lagu yang khusus ditulis untuk mengajarkan bahasa Inggris. Dalam penelitian Ratminingsih (2010), Ratminingsih \& Budasi (2014), Ratminingsih, Suwatra, \& Rasana, (2013), jenis lagu yang digunakan adalah lagu yang ditulis khusus, yang dinamakan lagu kreasi (scripted songs).

Merujuk pada hasil penelitian terdahulu, Ratminingsih (2010) membuktikan bahwa lagu merupakan salah satu teknik yang efektif untuk meningkatkan keterampilan mendengarkan bahasa Inggris siswa sekolah dasar Lab Undiksha Singaraja. Lebih lanjut penelitian Ratminingsih et al. (2013) membuktikan bahwa materi dan sintaks pembelajaran berbasis lagu dapat meningkatkan kompetensi bahasa Inggris siswa SD Lab Undiksha, dan penelitian Budasi, Ramendra, \& Suputra (2013) membuktikan bahwa media audio kelas 4 semester 1 dapat meningkatkan motivasi siswa dan kompetensi bahasa Inggris siswa SD No.2 Sukasada. Berdasarkan bukti tersebut, maka peneliti selanjutnya memandang perlu mengembangkan media audio selanjutnya, yakni di kelas lima. Hal ini dilakukan sebagai upaya melengkapi pembelajaran yang dilakukan oleh para guru SD di Kabupaten Buleleng yang mayoritas tidak berlatar belakang bahasa Inggris. Dengan demikian, memfasilitasi guru dengan media pendukung pembelajaran harus diupayakan secara terus menerus.

Berdasarkan uraian di atas,maka tujuan penelitian ini adalah untuk memberikan gambaran apakah media pembelajaran audio berupa lagu-lagu kreasi berbasis tema dapat meningkatkan kompetensi bahasa Inggris siswa kelas lima sekolah dasar yang ditunjukkan dari hasil belajar mereka setelah diberikan tindakan.

\section{METODE}

Desain penelitian dari uji emperis efektivitas penggunaan media audio adalah before and after treatment (Sugiyono, 2010). Lokasi penelitian adalah di SD No.1 Sukasada yang melibatkan 16 orang siswa kelas lima. Teknik pengumpulan data adalah melalui tes akhir, yaitu dengan memberikan 20 pertanyaan terkait dengan materi pembelajaran dengan topik Sports yang diajarkan sebanyak 2 sesi pembelajaran $4 \times 35$ menit. Pada sesi terakhir yaitu sesi 3 , siswa diberikan tes akhir berupa tes hasil belajar dengan mengangkat tema yang telah diajarkan, dan dilanjutkan dengan penyebaran kuesioner tentang motivasi belajar, yang mengarahkan mereka untuk memberikan Hasil penelitian dianalisis secara deskriptif. Hasil perhitungan nominal berupa skor rerata dideskripsikan secara kuantitatif, yaitu hasil tes awal dan tes akhir hasil belajar bahasa Inggris siswa yang berupa skor yang diperoleh sebelum diberikan tindakan dan sesudah diberikan tindakan. Skor rerata siswa dalam kompetensi bahasa Inggris sebelum diberikan media audio pembelajaran berbasis lagu kreasi dibandingkan dengan sesudah diberikan pembelajaran dengan menggunakan media. Data tambahan dari hasil kuesioner motivasi juga dianalisis secara kuantitatif untuk melihat bagaimana motivasi siswa terhadap pembelajaran 
dengan implementasi media audio berbasis lagu kreasi. Selanjutnya, hasil analisis dideskripsikan secara kualitatif untuk mengetahui efektivitas dari media pembelajaran yang digunakan.

\section{HASIL DAN PEMBAHASAN}

Setelah melalui uji validitas isi dan kualitas media dari kedua ahli, maka media audio tersebut siap untuk diujikan secara emperis melalui sebuah penelitian yaitu before and after treatment (Sugiyono, 2010) untuk melihat efektivitas media yang dikembangkan dalam meningkatkan hasil belajar bahasa Inggris siswa kelas lima SD. Penjajagan tempat penelitian di SD No.1 Sukasada sudah dibicarakan dengan kepala sekolah dan guru pengampu mata pelajaran Bahasa Inggris di sekolah tersebut. Baik Kepala Sekolah dan guru sudah menyetujui kegiatan penelitian akan dilakukan di SD No. 1 Sukasada yang dimulai tanggal 2 September 2014 sampai dengan 16 September 2014 (3 minggu). Dari 3 sesi yang direncanakan, dua sesi digunakan untuk melaksanakan pembelajaran dengan tema Sports, dan satu sesi untuk menyelenggarakan tes akhir (post test). Sebelum diberikan tindakan (treatment), kompetensi siswa kelas lima SD No.1 Sukasada yang diambil dari skor tes sumatif semester 2 ketika mereka duduk di kelas empat adalah sebagai berikut: persepsi terhadap pemanfaatan media audio berbasis lagu dalam pembelajaran.

Tabel 1. Skor Awal Siswa sebelum Tindakan

\begin{tabular}{clc}
\hline No & \multicolumn{1}{c}{ Nama Siswa } & Skor \\
\hline 1 & Komang Very Gunawan & 5,85 \\
2 & Aditya Wisnu Budi Kurniawan & 3,23 \\
3 & Komang Agus Adi Krisnanda & 6,76 \\
4 & Ngurah Arya Darma Wiguna & 5,07 \\
5 & Ida Ayu Kade Citra Dwitya Citta & 6,0 \\
6 & Komang Gina Kusuma Dewi & 8,76 \\
7 & Komang Linda Pratiwi & 7,07 \\
8 & Ni Luh Putu Oktavianingsih & 8,31 \\
9 & Komang Roby Arya Prananda & 8,46 \\
10 & Ni Putu Sania Cantika Dewi & 6,92 \\
11 & Kadek Suci Handayani & 9,69 \\
12 & Komang Urip Harta Darma & 6,46 \\
13 & Ketut Mangku Rini & 3,85 \\
14 & Ida Bagus Indra Paramartha & 6,46 \\
15 & Ida Ayu Kade Bulan Cahyaninggrat & 8,76 \\
16 & Krisnawati & 5,53 \\
& Skor Total & 107,18 \\
& Rerata Skor & 6,69 \\
\hline
\end{tabular}


Dari Tabel 1 di atas dan merujuk pada Tabel kriteria penilaian pada Tabel 2 di bawah, dapat dilihat bahwa kompetensi siswa kelas lima SD No.1 Sukasada sebelum diberikan tindakan adalah 6,69 yang terkategori cukup.

Tabel 2. Skor Patokan dan Kriteria yang Digunakan di SD

\begin{tabular}{cl}
\hline Skor & \\
\hline $8,6-10$ & Sangat baik \\
$7,1-8,5$ & baik \\
$5,6-7$ & cukup \\
$4,0-5,5$ & Kurang \\
$0-3,9$ & Sangat Kurang \\
\hline
\end{tabular}

Setelah diberikan dua kali sesi pembelajaran melalui pemanfaatan kreasi, hasil tes akhir adalah seperti pada media audio pembelajaran berbasis lagu Tabel 3.

Tabel 3. Skor Tes Akhir setelah Tindakan

\begin{tabular}{clc}
\hline No & \multicolumn{1}{c}{ Nama Siswa } & Skor \\
\hline 1 & Komang Very Gunawan & 8,5 \\
2 & Aditya Wisnu Budi Kurniawan & 7,5 \\
3 & Komang Agus Adi Krisnanda & 9,0 \\
4 & Ngurah Arya Darma Wiguna & 7,0 \\
5 & Ida Ayu Kade Citra Dwitya Citta & 10 \\
6 & Komang Gina Kusuma Dewi & 9,5 \\
7 & Komang Linda Pratiwi & 7,5 \\
8 & Ni Luh Putu Oktavianingsih & 9,5 \\
9 & Komang Roby Arya Prananda & 8,0 \\
10 & Ni Putu Sania Cantika Dewi & 7,5 \\
11 & Kadek Suci Handayani & 9,5 \\
12 & Komang Urip Harta Darma & 8,0 \\
13 & Ketut Mangku Rini & 6,0 \\
14 & Ida Bagus Indra Paramartha & 9,5 \\
15 & Ida Ayu Kade Bulan Cahyaninggrat & 6,5 \\
16 & Krisnawati & 9,5 \\
& Skor Total & 133 \\
& Rerata Skor & 8,31 \\
\hline
\end{tabular}

Tabel 3 menunjukkan bahwa setelah diberikan tindakan berupa pembelajaran yang memanfaatkan media audio berupa $C D$ yang berisi lagu- 
lagu kreasi, skor siswa mengalami peningkatan pada capaian skor rerata yaitu 8,31 yang terkategori baik. Capaian tersebut mengindikasikan bahwa media audio yang berisi lagu-lagu kreasi efektif membantu meningkatkan kemampuan bahasa Inggris siswa. Yang menarik dari temuan ini adalah beberapa siswa yaitu 2 orang mendapatkan skor di bawah 3, yang tergolong sangat kurang dan 2 orang mendapatkan skor antara 4 sd.5,5 yang tergolong kurang sebelum diberikan tindakan, mereka mampu meningkatkan kemampuan bahasa Inggrisnya yaitu menjadi masing-masing, 7,5 dan 6,0 dan 70 dan 9,5 setelah diberikan tindakan melalui pemanfaatan media audio. Hal ini membuktikan bahwa mereka terbantu meningkatkan hasil belajar melalui kegiatan yang menarik baginya, yakni melalui media audio. Bukti ini menegaskan bahwa media audio yang berisi lagu-lagu kreasi dalam bentuk CD pembelajaran efektif meningkatkan hasil belajar siswa. Hasil penelitian ini mendukung penelitian terdahulu (Cuestas Cifuentes, 2006; Hidayanti, 2011; Jadal, 2011; Kömür, Saraç, \& Şeker, 2005; Ratminingsih, 2010; Ratminingsih et al., 2013; Sevik, 2011) bahwa penggunaan lagu dalam pembelajaran merupakan strategi pembelajaran yang efektif bukan hanya untuk meningkatkan hasil belajar bahasa Inggris mereka secara spesifik pada komponen kebahasaan, seperti kosakata, tetapi juga pada keterampilan berbahasa yakni mendengarkan dan berbicara. Hasil penelitian ini juga sejalan dengan Griffee (1992) bahwa lagu dapat menciptakan atmosfer belajar yang menyenangkan, sehingga dapat memberikan kesenangan bukan hanya bagi siswa yang mampu, tetapi juga yang kurang mampu, yang berdampak pada peningkatan hasil belajar mereka. Selain itu, lagu dapat memberikan input kebahasaan (language input) yang mengajarkan percakapan, kosakata, struktur gramatika, lafal, latihan pola dan pemantapan ingatan. Dengan demikian, semua komponen kebahasaan dan keterampilan berbahasa dapat diintegrasikan melalui lagu.

Temuan ini didukung oleh Yassaei (2012) bahwa media sangat disadari dapat menciptakan konteks bermakna dalam pembelajaran bahasa Inggris dalam berbagai format, seperti cetak, audio, dan visual, yang dalam penelitian ini memanfaatkan format audio yang dapat diputar dengan $C D$ player atau komputer. Konteks kebahasaan yang dibangun melalui lagu kreasi terbukti dapat meningkatkan minat, motivasi dan keterlibatan siswa dalam belajar, sehingga berefek terhadap peningkatan hasil belajar. Dengan demikian, hasil penelitian tersebut mendukung Hamalik (dalam Arsyad, 2011)) yang menegaskan pemakaian media pembelajaran dalam proses belajar mengajar dapat membangkitkan keinginan dan minat yang baru, membangkitkan motivasi dan rangsangan kegiatan belajar, dan bahkan membawa pengaruh psikologis terhadap siswa. Terlebih bagi pebelajar anak-anak,yang masih pada fase perkembangan operational concrete, dunia fisik menjadi fokus pembelajaran, yang dalam penelitian ini diupayakan denganpemanfaatan objek audio ke dalam pembelajaran, sebagai upaya untuk memvariasikan pembelajaran. Hal ini sesuai dengan pendapat Scott \& Ytreberg (1990) dan Shin (2006) bahwa untuk meningkatkan perhatian dan 
keterlibatan siswa dalam belajar, maka strategi utama adalah melalui pemanfaatan alat pendukung atau media pembelajaran yang bervariasi.

Selain itu, temuan tambahan dari hasil angket yang menjaring motivasi mereka belajar bahasa Inggris membuktikan bahwa 16 siswa (100\%) menyatakan pendapatnya bahwa mereka sangat setuju dengan digunakannya lagu-lagu dalam belajar, karena lagu membuat pelajaran menarik, menyenangkan, sehingga mereka termotivasi dan mendorong mereka aktif berpartisipasi serta merangsang rasa ingin tahu mereka terhadap apa yang diajarkan guru secara bersungguhsungguh. Temuan ini sesuai dengan pendapat Csabay (2006) bahwa motivasi memegang peranan penting untuk kesuksesan pembelajaran. Motivasi mereka dalam belajar dapat ditingkatkan melalui pemanfaatan media yang tepat, seperti melalui media audio lagu-lagu. Di samping itu mereka juga menegaskan bahwa pelajaran melalui penggunaan media audio berisi lagu-lagu memudahkan mereka memahami materi pelajaran yang membuat mereka yakin bahwa pelajaran menjadi lebih bermanfaat, sehingga mereka percaya dapat berhasil dalam tes dan meningkatkan kemampuan atau hasil belajarnya. Hasil penelitian ini mendukung penelitian Ratminingsih (2010) dan Ratminingsih et al. (2013) yang membuktikan bahwa motivasi belajar siswa meningkat dengan pemanfaatan lagu kreasi (scripted songs) dalam pembelajaran bahasa Inggris.

\section{SIMPULAN DAN SARAN}

Berdasarkan analisis uji emperis melalui desain before and after treatment, media audio terbukti efektif untuk meningkatkan hasil belajar bahasa Inggris siswa kelas lima sekolah dasar, yang dibuktikan dari peningkatan hasil belajar dari 6,69 (cukup) sebelum tindakan menjadi 8,31 (baik) setelah tindakan. Di samping itu, siswa juga memiliki persepsi positif terhadap pemanfaatan media audio berbasis lagu kreasi dalam pembelajaran, yang terbukti dari hasil kuesioner bahwa semua siswa $(100 \%)$ sangat setuju dengan pemanfaatan media audio berbasis lagu yang dapat meningkatkan motivasi belajar mereka karena melalui pemanfaatan lagu, mereka menyatakan bahwa pembelajaran menjadi lebih menyenangkan, menarik, sehingga lebih mudah memahami pelajaran.

Hal-hal yang dapat disarankan berdasarkan hasil penelitian ini adalah (1) Dengan adanya penyediaan media audio yang dikembangkan oleh peneliti, para guru pengampu mata pelajaran Bahasa Inggris diharapkan dapat memvariasikan pembelajaran dengan menggunakan media inovatif, seperti CD pembelajaran yang berisi lagu-lagu kreasi, yang dapat meningkatkan motivasi dan partisipasi siswa belajar, dan (2) Oleh karena media audio CD pembelajaran yang berisi lagu-lagu ini telah terbukti dapat meningkatkan hasil belajar siswa, para guru disarankan untuk memaksimalkan penggunaan media pembelajaran untuk menghadirkan pembelajaran yang menyenangkan dan menarik, agar dapat memaksimalkan kompetensi Bahasa Inggris siswa. 


\section{DAFTAR PUSTAKA}

Arsyad, A. (2011). Media pembelajaran. Jakarta: PT Raja Grafindo Persada.

Brewster, J., Ellis, G., \& Girard, D. (1992). The primary English teacher's guide. Penguin English.

Brown, H. D. (1994). Teaching by Principles: An Interactive Approach to Language Pedagogy. New Jersey: Prentice Hall Regents.

Budasi, I. G., Ramendra, D. P., \& Suputra, P. E. D. (2013). Pengembangan Media Pembelajaran Audio Bahasa Inggris Lagu-Lagu Kreasi Khusus (Scripted Songs) Berbasis Tema. Laporan Penelitian.

Chitravelu, N., Sithamparam, S., \& Teh, S. C. (2005). ELT methodology: Principles and practice. Oxford Fajar.

Csabay, N. (2006). Using Comic Strips in Language Classes. In English Teaching Forum (Vol. 44, pp. 2426).

Cuestas Cifuentes, M. (2006). Songs in the English class: A strategy to encourage tenth graders' oral production. Profile Issues in Teachers Professional Development, (7), 47-58.

Dimyati, M. (2006). Belajar dan pembelajaran. Jakarta: Rineka Cipta.

Gagne, R. M., \& Briggs, L. J. (1974). Principles of instructional design. Holt, Rinehart \& Winston.

Griffee, D. T. (1992). Songs in action. Prentice Hall.
Harmer, J. (1983). The practice of English language teaching. ERIC.

Hidayanti, F. (2011). Peningkatan keterampilan berbicara Bahasa Inggris melalui lagu dan permainan pada siswa kelas IV di SDN Madiredo 02 Kecamatan Pujon Kabupaten Malang. Jurusan Kependidikan Sekolah Dasar \& Prasekolah-Fakultas IImu Pendidikan UM.

Jadal, M. M. (2011). A study of effectiveness of the audio-visualaids in teaching and learning of English at primary level in ZP Primary Schools of Solapur District. Indian Streams Research Journal, 1(7), 1-21.

Kömür, Ş., Saraç, G., \& Şeker, H. (2005). Teaching English through Songs (Practice in Muğla/Turkey). Sosyal Bilimler Enstitüsü Dergisi (íLKE), 15, 120.

Mol, H. (2012). Using song in the classroom.

Murphey, T. (1992). Music and song. Oxford University Press.

Paul, D., \& Chan, M. (2010). Teaching English to children in Asia. Pearson Longman Asia.

Ramendra, D. P., \& Ratminingsih, N. M. (2006). Studi pemanfaatan alat bantu pembelajaran (Audio Visual Aids) dalam proses belajar mengajar mata pelajaran bahasa Inggris di sekolah dasar di Kota Singaraja: Upaya menguaktualisasikan kurikulum berbasis kompetensi. Laporan Penelitian. Singaraja: Universitas Pendidikan Ganesha.

Jurnal Pendidikan Indonesia|37 
Ramendra, D. P., \& Ratminingsih, N. M. (2007). Pemanfaatan Audio-Visual Aids (AVA) dalam proses belajar mengajar mata pelajaran bahasa Inggris di sekolah dasar. Jurnal Penelitian Dan Pengembangan Pendidikan, 1(2), 78-95.

Ratminingsih, N. M. (2010). Pengaruh teknik pembelajaran dan tipe kepribadian terhadap keterampilan mendengarkan bahasa Inggris: Studi eksperimen pada siswa SD LAB Undiskha Singaraja. Disertasi Doktor.

Ratminingsih, N. M., \& Budasi, I. G. (2012). Pelatihan pemanfaatan lagu-lagu kreasi khusus (scripted songs) dalam pembelajaran bahasa Inggris berbasis tema di sekolah dasar di Kecamatan Sukasada Kabupaten Buleleng. Laporan P2M. Universitas Pendidikan Ganesha.

Ratminingsih, N. M., \& Budasi, I. G. (2014). Pengembangan media audio pembelajaran bahasa Inggris berbasis lagu kreasi di kelas lima sekolah dasar. Laporan Penelitian. Universitas Pendidikan Ganesha Singaraja.

Ratminingsih, N. M., Suwatra, I. I. W., \& Rasana, I. (2013). Pengembangan model pembelajaran bahasa Inggris induktif berbasis lagu kreasi (scripted songs): Inovasi pembelajaran integratif dan holistik dengan insersi nilai budaya dan karakter bangsa. Laporan Penelitian Tidak Diterbitkan. Singaraja: Universitas Pendidikan Ganesha.

Schoepp, K. (2001). Reasons for using songs in the ESL/EFL classroom. The Internet TESL Journal, 7(2), 14.

Scott, W. A., \& Ytreberg, L. H. (1990). Teaching English to children. Longman London.

Sevik, M. (2011). Teacher views about using songs in teaching English to young learners. Educational Research and Reviews, 6(21), 1027.

Shin, J. K. (2006). Ten Helpful Ideas for Teaching English to Young Learners. In English Teaching Forum (Vol. 44, p. 2).

Shtakser, I. (2012). Using music and songs in the foreign language classroom.

Yassaei, S. (2012). Using Original Video and Sound Effects to Teach English. In English teaching forum (Vol. 50, pp. 12-16). 